\title{
Singular Structural Features on Humic Fractions in Solution: Statistical Analysis of Diverse Analytical Techniques Spectra
}

\section{Roberto Baigorri* \\ R\&D Dep. \\ CIPAV-Roullier Group \\ Inabonos \\ Polígono Arazuri-Orkoien \\ 31160, Orkoien, Spain}

\section{Marta Fuentes}

Dep. of Chemistry and Soil Science

Univ. of Navarra

31080, Pamplona, Spain

\section{Francisco J. González-Vila}

Centro de Ciencias Medioambientales CSIC

Serrano $115 B$

28006 Madrid, Spain

\section{José M. García-Mina}

R\&D Dep.

CIPAV-Roullier Group

Inabonos

Polígono Arazuri-Orkoien

31160, Orkoien, Spain

and

Dep. of Chemistry and Soil Science

Univ. of Navarra

31080, Pamplona, Spain
An adequate knowledge of the chemical and structural features that characterize the main fractions of humic substances in solution is of great interest to better understand a number of processes occurring in nature. Qualitative analysis of the spectra derived from diverse analytical techniques is frequently complicated, however, partially due to the quantity and complexity of the data. In this context, multivariate statistical analysis has proven to be a useful tool to integrate and interpret all this information. In this study, we applied Pareto analysis to the spectrum data derived from the application of diverse analytical techniques to several samples of humic substances. The humic substances considered in the study belong to the following groups: gray humic acid (GHA), brown humic acid (BHA), and fulvic acid (FA). The analytical techniques applied were ultraviolet-visible light, synchronous fluorescence, and Fourier transform infrared spectroscopies, ${ }^{13} \mathrm{C}$ nuclear magnetic resonance spectrometry, and pyrolysis gas chromatography-mass spectrometry. The results show the efficiency of Pareto analysis at discriminating between the different groups of humic substances. This discrimination corresponded to specific spectral regions for each group, which corresponded to singular structural features. Thus, GHA presented a marked aliphatic character and low functionality. The BHA group presented high structural homogeneity characterized by a high aromatic character, including significant ring condensation and complexity, and significant functionality. The FA group was very disperse, with high diversity in functional arrangements of simpler organic molecules, low condensed aromatic rings, and a very high concentration of $\mathrm{O}$-containing functional groups that might be involved in metal intermolecular bridges. A discriminant analysis of data derived from the Pareto analysis confirmed the validity of these singular structural features as representative of each humic substance group.

Abbreviations: BHA, brown humic acid; FA, fulvic acid; FTIR, Fourier transform infrared; GCMS, gas chromatography-mass spectrometry; GHA, gray humic acid; HS, humic substances; NMR, nuclear magnetic resonance spectrometry; PCA, principal components analysis; SFS, synchronous fluorescence spectroscopy; SRFA, Suwannee River reference fulvic acid; UV-Vis, ultraviolet-visible light spectroscopy; WPFA, Waskish peat reference fulvic acid; ZGHA, Czech gray humic acid.

$\mathrm{H}$ umic substances (HS) are the major source of C in soils (Stevenson, 1994). They are formed during the decomposition of plant and animal residues by chemical reactions (Sparks, 1995) and are resistant to microbial degradation (Lovley et al., 1996). The chemical nature and structural features of HS, however, are under continuous debate. Both the heterogeneity of the fresh organic residues and the possible existence of different degradation-humification pathways involve the presence in HS of diverse functional and structural compositions, although they normally present common qualitative patterns (Schnitzer, 1991; Stevenson, 1994). As a consequence of this complexity, the HS classification is ordinarily operational, and it is principally based on their solubility at different $\mathrm{pH}$ values and ionic strengths $(I)$. According to this classical classification, HS in solution can be subdivided into the following molecular fractions: GHA, which is the molecular fraction insoluble at acid $\mathrm{pH}$ and soluble at alkaline $\mathrm{pH}$ but insoluble at neutral $\mathrm{pH}$ and high I; $\mathrm{BHA}$, which is the molecular fraction insoluble at acid $\mathrm{pH}$ but soluble at alkaline $\mathrm{pH}$ and also at high $I$; and finally, FA, which is the molecular fraction soluble at acid $\mathrm{pH}$ and at both low and high $I$ (Baigorri et al., 2007). 
In the past years, many researchers have deepened the characterization of HS using several analytical techniques. These techniques include ultraviolet-visible light spectroscopy (UV-Vis), Fourier-transform infrared spectroscopy (FTIR), synchronous fluorescence spectroscopy (SFS), solid-state ${ }^{13} \mathrm{C}$ nuclear magnetic resonance spectrometry (NMR), and pyrolysis gas chromatography-mass spectrometry (GC-MS). Recently Baigorri et al. (2007) analyzed several humic fractions using a complementary multianalytical technique strategy and analyzed the obtained results only from a qualitative point of view. This study suggested that GHA accumulated principally aliphatic structures, whereas BHA was more aromatic and functionalized than GHA. Finally, FA presented less transformed molecules and simpler aromatic arrangements.

The great complexity and quantity of spectral data, however, makes both a global and complete analysis of the spectra very difficult (Stevenson, 1994; Schnitzer, 1991; Baigorri et al., 2007, 2008). Previous studies have shown the usefulness of statistical methods for the quantitative or semiquantitative analysis of very complex data sets, such as those derived from mass spectroscopy (Beauchemin et al., 2002; Boehme et al., 2004; Celano et al., 2008; Lucio and Schmitt-Kopplin, 2006; Moreda-Piñeiro et al., 2006; Peña-Méndez et al., 2005; White et al., 2007; Šmejkalová and Piccolo, 2008). Among these statistical methods, the use of a specific method of principal components analysis (PCA), Pareto analysis, has proven to be very promising (Baigorri et al., 2008). Principal components analysis reduces the data set but thereby loses some information (Baigorri et al., 2008; Beauchemin et al., 2002; Boehme et al., 2004; Celano et al., 2008; Lucio and Schmitt-Kopplin, 2006; Moreda-Piñeiro et al., 2006; PeñaMéndez et al., 2005; White et al., 2007; Šmejkalová and Piccolo, 2008). Pareto analysis is a statistical technique used in decision making that selects those facts that produce a significant overall effect. It uses the Pareto principle: a large majority of consequences (80\%) are produced by a few key causes $(20 \%)$. This complementary statistical approach allows analysis of all of the data derived from the use of the different analytical techniques (Karuppusami and Gandhinathan, 2006). Likewise, it facilitates the identification of those structural features that characterize and discriminate each humic fraction.

In this context, the aim of this study was to use the Pareto methodology for the analysis of data derived from the application of different analytical techniques (UV-Vis, FTIR, ${ }^{13} \mathrm{C}-\mathrm{NMR}, \mathrm{SFS}$, and pyrolysis GC-MS) for the analysis of several HS samples. This analysis permits us to evaluate which region (or regions) of the spectrum is more relevant to define each HS fraction. Finally, we have performed a discriminant analysis of the PCA-Pareto data to assess the capacity of these specific structural markers for grouping the different HS fractions (GHA, $\mathrm{BHA}$, and FA).

\section{MATERIALS AND METHODS Humic Materials}

Soil humic acids from different origins were used in this study: a young brown coal humic acid (leonardite) extracted from a soil sample from the Czech Republic (Novák et al., 2001), a commercial humic acid from Sigma-Aldrich Corporation (St. Louis, MO), and a leonardite standard humic acid from the International Humic Substances Society (IHSS). Two fulvic acids from IHSS standards were included in this work: Suwannee River reference fulvic acid and Waskish peat reference fulvic acid.

\section{Extraction Procedure}

The different humic fractions were isolated following an IHSS procedure (Stevenson, 1994; Swift, 1996). Humic acids were fractionated in GHA and BHA fractions according to Swift (1985). Briefly, we dissolved $12 \mathrm{~g} \mathrm{~L}^{-1}$ of humic acid in $2 \mathrm{~mol} \mathrm{~L}^{-1} \mathrm{KCl}$ at $\mathrm{pH} 7$. After $12 \mathrm{~h}$ of continuous stirring, the suspension was centrifuged ( 7650 relative centrifugal force). The solution containing BHA and the precipitate containing GHA were purified following an IHSS procedure (Stevenson, 1994; Swift, 1996) until the ash contents were $<2 \%$. The fractions were purified and freeze-dried. The samples were named as follows: Aldrich gray humic acid (AGHA), Aldrich brown humic acid (ABHA), leonardite standard gray humic acid (LGHA), leonardite standard brown humic acid (LBHA), Czech gray humic acid (ZGHA), Czech brown humic acid (ZBHA), Waskish peat reference fulvic acid (WPFA), and Suwannee River reference fulvic acid (SRFA).

\section{Solid-State Carbon-13 Nuclear Magnetic Resonance Spectrometry}

Solid-state ${ }^{13} \mathrm{C}-\mathrm{NMR}$ spectra were obtained with a Bruker Avance AV-400WB (Bruker Corp., Billerica, MA) spectrometer $(9.4 \mathrm{~T})$ at 100.47 MHz, using the cross-polarization magic angle spinning technique, with a rotation speed of $12 \mathrm{kHz}, 90^{\circ}$ pulse width, 30 -ms acquisition time, and 4.0-s delay.

\section{Synchronous Fluorescence Spectroscopy}

Fluorescence spectra were performed on a PerkinElmer (Waltham, MA) LS50B fluorescence spectrophotometer, under the same conditions described by Peuravuori et al. (2002).

\section{Fourier-Transform Infrared Spectroscopy}

The KBr Pellets were prepared by mixing $1 \mathrm{mg}$ of each freeze-dried sample with $100 \mathrm{mg}$ of $\mathrm{KBr}$ until homogenized. Infrared spectra were recorded from these pellets with a Nicolet Magna-IR 550 spectrometer (Nicolet Instruments, Madison, WI) across the 4000 to $400 \mathrm{~cm}^{-1}$ range, with a resolution of $2 \mathrm{~cm}^{-1}$.

\section{Pyrolysis Gas Chromatograpy-Mass Spectometry}

Pyrolysis GC-MS was performed on an Agilent 6890 Network gas chromatographic system (Agilent Technologies, Santa Clara, CA) coupled to an Agilent 5973 Network mass selective detector (electron impact at $70 \mathrm{eV}$ ). The column (fused silica, 30 by $0.25 \mathrm{~m}$ by $0.25 \mathrm{~mm}$ ) was coated with a DB5MS. About $0.5 \mathrm{mg}$ of sample was loaded in the cup of a PY2020iD pyrolyser (Frontier Laboratories, Fukushima, 
Japan), and heated at $500^{\circ} \mathrm{C}$ for $1 \mathrm{~min}$. The pyrolysis products were injected directly through a deactivated needle inserted in the GC-MS injector. The GC injector temperature was $250^{\circ} \mathrm{C}$, and the interface between the pyroprobe and the GC system was kept at $350^{\circ} \mathrm{C}$. The temperature program was 50 to $100^{\circ} \mathrm{C}$ at a rate of $30^{\circ} \mathrm{C} \mathrm{min}-1$, followed by 100 to $300^{\circ} \mathrm{C}$ at $10^{\circ} \mathrm{C} \mathrm{min}^{-1}$.

\section{Ultraviolet-Visible Light Spectroscopy}

The UV-Vis studies were performed by molecular absorption in the 250- to 680-nm range with a HP 8453 spectrophotometer (Agilent Technologies), in 1.000-cm path length quartz cuvettes.

\section{Statistical Software}

The analytical data from all analytical techniques used were treated to obtain Pareto analysis PCA by MarkerView 1.1 software (Applied Biosystems, Foster City, CA). Multivariate data analyses (discriminant analysis) were performed by SPSS 12.0 software (SPSS Inc., Chicago).

\section{RESULTS AND DISCUSSION Pareto Analysis}

The PCA-Pareto analyses of the ${ }^{13} \mathrm{C}-\mathrm{NMR}$ data show that the HS samples studied were separated into three different groups that coincided with their different HS classes: GHA, BHA, and FA (Fig. 1a and 1b). If we identify the spectrum
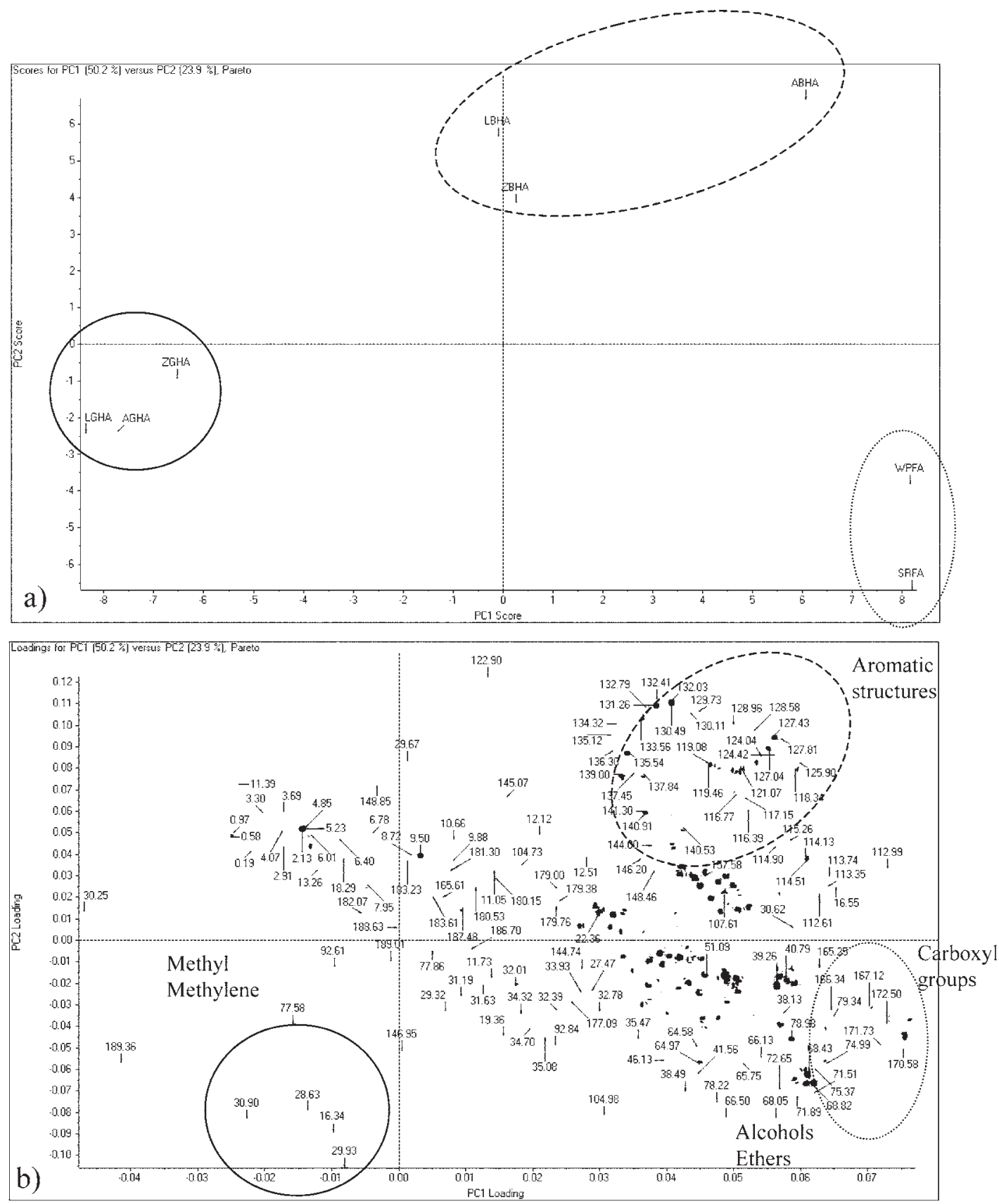

Fig. 1. MarkerView 1.1 principal component (PC) analysis graphics for ${ }^{13} \mathrm{C}$ nuclear magnetic resonance spectrometry: (a) sample grouping in $\mathrm{PC}$ scores, and (b) structural association sample signal in PC loadings (ABHA, Aldrich brown humic acid; AGHA, Aldrich gray humic acid; LBHA, leonardite standard brown humic acid; LGHA, leonardite standard gray humic acid; SRFA, Suwannee River reference fulvic acid; WPFA, Waskish peat reference fulvic acid; ZBHA, Czech brown humic acid; ZGHA, Czech gray humic acid). 
region that defines and discriminates among each HS group, we observe that it corresponds with a range of certain well-defined chemical structures. Thus, the corresponding area for the GHA fractions is associated with the 10- to 50-ppm range, which is related to methyl and methylene (aliphatic) structures (Mahieu et al., 2002; Mao et al., 2000; Wang and Xing, 2005). The area for $\mathrm{BHA}$ fractions is associated with the 108- to $145-\mathrm{ppm}$ range that corresponds with aromatic structures (Mahieu et al., 2002; Mao et al., 2000; Wang and Xing, 2005). Finally, for FA frac- tions, the area is associated with both the 60- to 96- and 162- to 190-ppm ranges, which are related to alcohols and ethers, and carboxyl structures, respectively.

The Pareto analysis of the SFS spectra also rendered specific areas corresponding to each HS fraction (Fig. $2 a$ and $2 b$ ). Thus, the GHA area corresponds to $300-$ to $350-\mathrm{nm}$ peak signals, which are related to naphthalene and its derivatives (Peuravuori et al., 2002). The BHA area, however, corresponds to 450- to $600-\mathrm{nm}$ peak signals, which are related to polycyclic aromatics

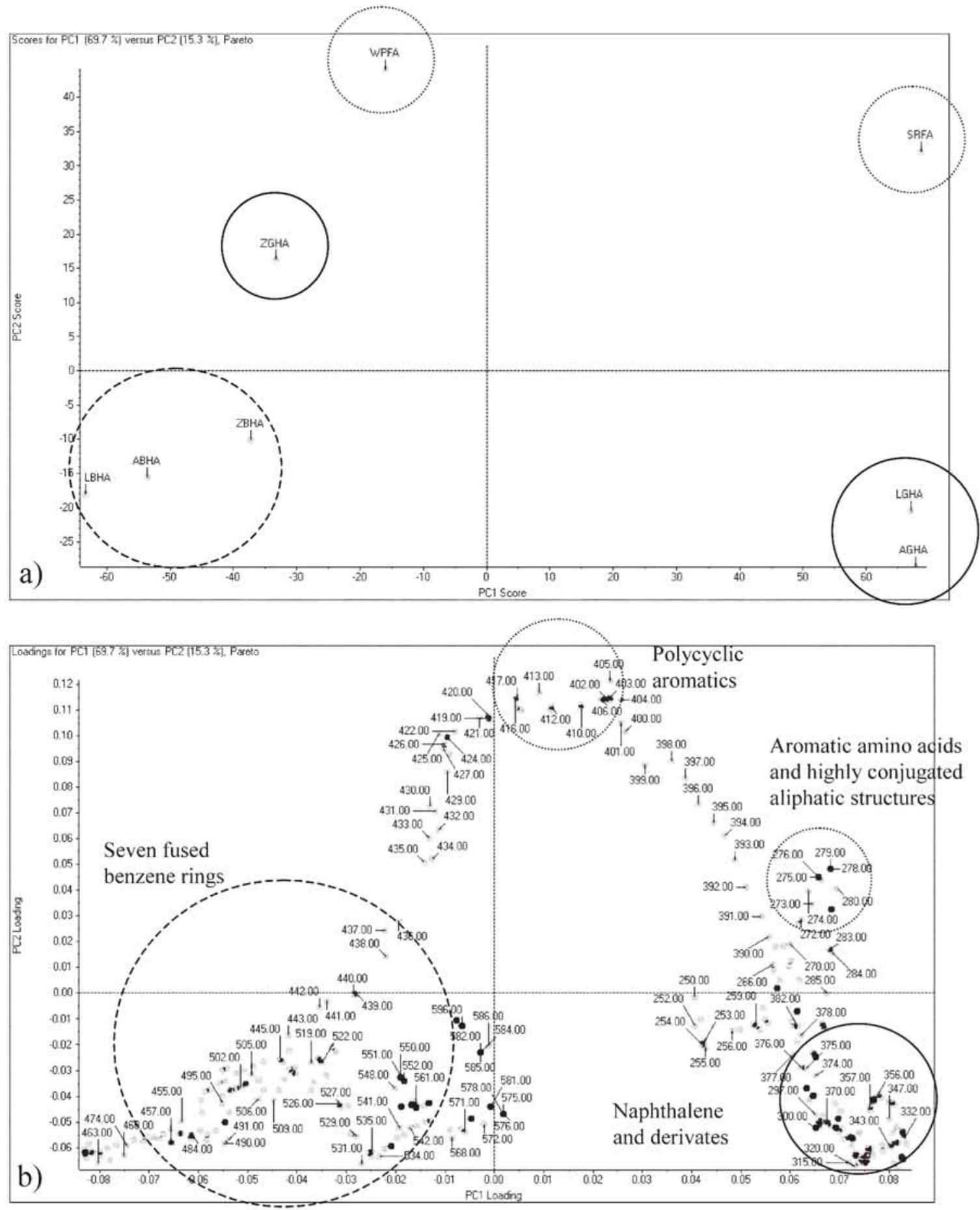

Fig. 2. MarkerView 1.1 principal component (PC) analysis graphics for synchronous fluorescence spectroscopy: (a) sample grouping in PC scores, and (b) structural association sample signal in PC loadings (ABHA, Aldrich brown humic acid; AGHA, Aldrich gray humic acid; LBHA, leonardite standard brown humic acid; LGHA, leonardite standard gray humic acid; SRFA, Suwannee River reference fulvic acid; WPFA, Waskish peat reference fulvic acid; ZBHA, Czech brown humic acid; ZGHA, Czech gray humic acid). 
consisting of about seven fused benzene rings (Peuravuori et al., 2002). Finally, two areas are involved for FA samples. The first one, around 250 to $300 \mathrm{~nm}$, is related to aromatic amino acids and some other volatile acids containing highly conjugated aliphatic structures (Peuravuori et al., 2002); the second one, around 400 to $450 \mathrm{~nm}$, is related to polycyclic aromatics consisting of about five fused benzene rings (Peuravuori et al., 2002).

As for the application of Pareto analysis to FTIR spectra, we can observe that the GHA fraction is grouped (Fig. 3a) and associated with aliphatic C-H stretching $\left(2850-2950 \mathrm{~cm}^{-1}\right.$ in Fig.

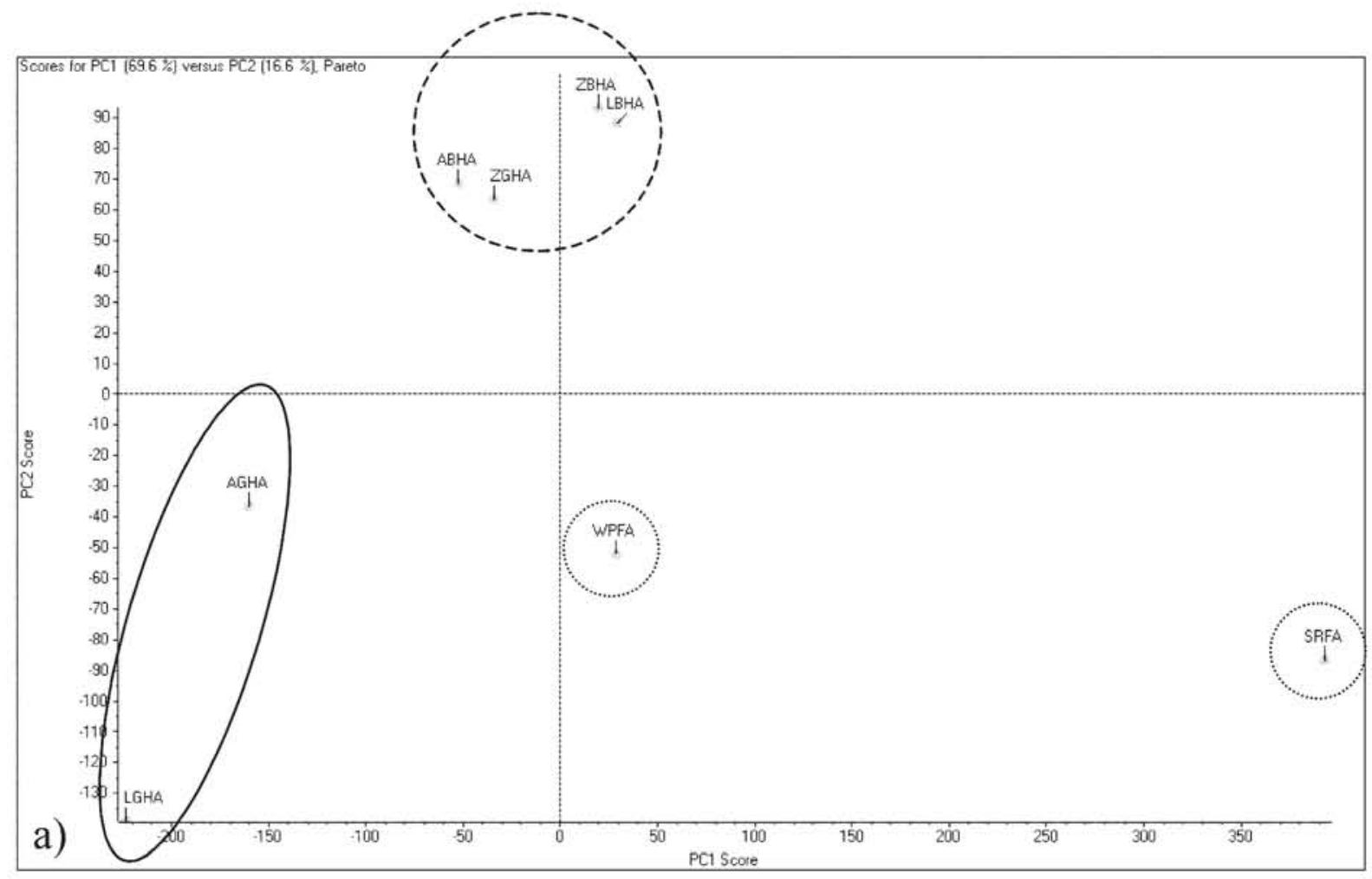

Structural vibrations

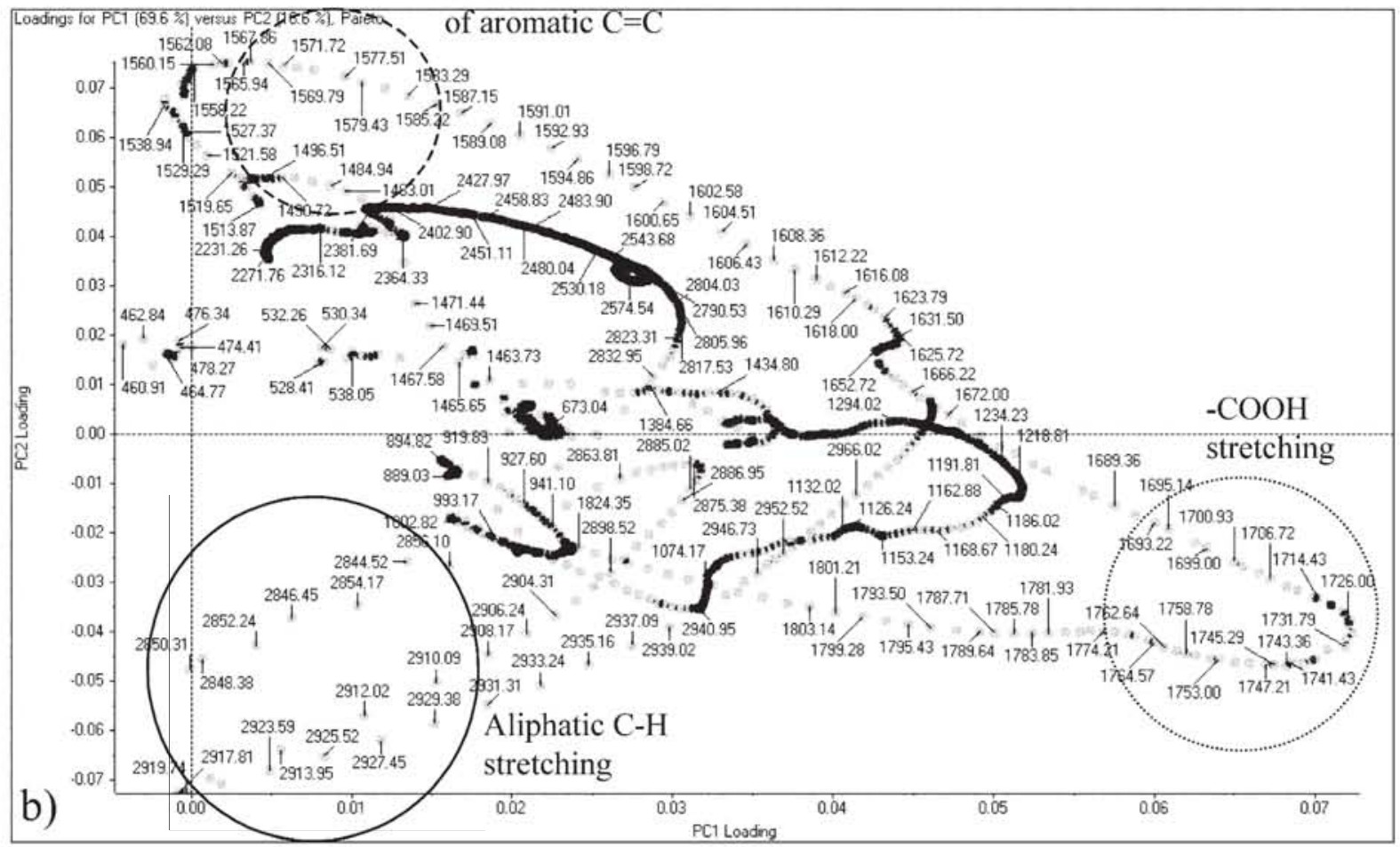

Fig. 3. MarkerView 1.1 principal component (PC) analysis graphics for Fourier-transform infrared spectroscopy: (a) sample grouping in PC scores, and (b) structural association sample signal in PC loadings (ABHA, Aldrich brown humic acid; AGHA, Aldrich gray humic acid; LBHA, leonardite standard brown humic acid; LGHA, leonardite standard gray humic acid; SRFA, Suwannee River reference fulvic acid; WPFA, Waskish peat reference fulvic acid; ZBHA, Czech brown humic acid; ZGHA, Czech gray humic acid). 
3b). On the other hand, the BHA fraction (Fig. 3a) is associated with structural vibrations of aromatic $\mathrm{C}=\mathrm{C}\left(1550-1650 \mathrm{~cm}^{-1}\right.$ in Fig. 3b). Regarding the FA samples, only the SRFA is associated with $-\mathrm{COOH}$ stretching (around $1700 \mathrm{~cm}^{-1}$ in Fig. 3b), whereas the WPFA sample is grouped between the GHA fractions and SRFA, and the ZGHA sample is grouped close to the BHA fraction.
Regarding pyrolysis GC-MS data, the Pareto analysis rendered the following structural patterns (Fig. $4 \mathrm{a}$ and $4 \mathrm{~b}$ ). The GHA samples appear disperse but associated with peaks corresponding to alkanes and alkenes from $\mathrm{C}_{16}$ to $\mathrm{C}_{28}$, including terpenes. The $\mathrm{BHA}$ fraction samples appear much more grouped and are related to peaks corresponding to aromatic structures (anthracene, benzothiophene, and phenanthrene). Finally, the FA samples are associated with furfurals and furans (Fig. 4b).
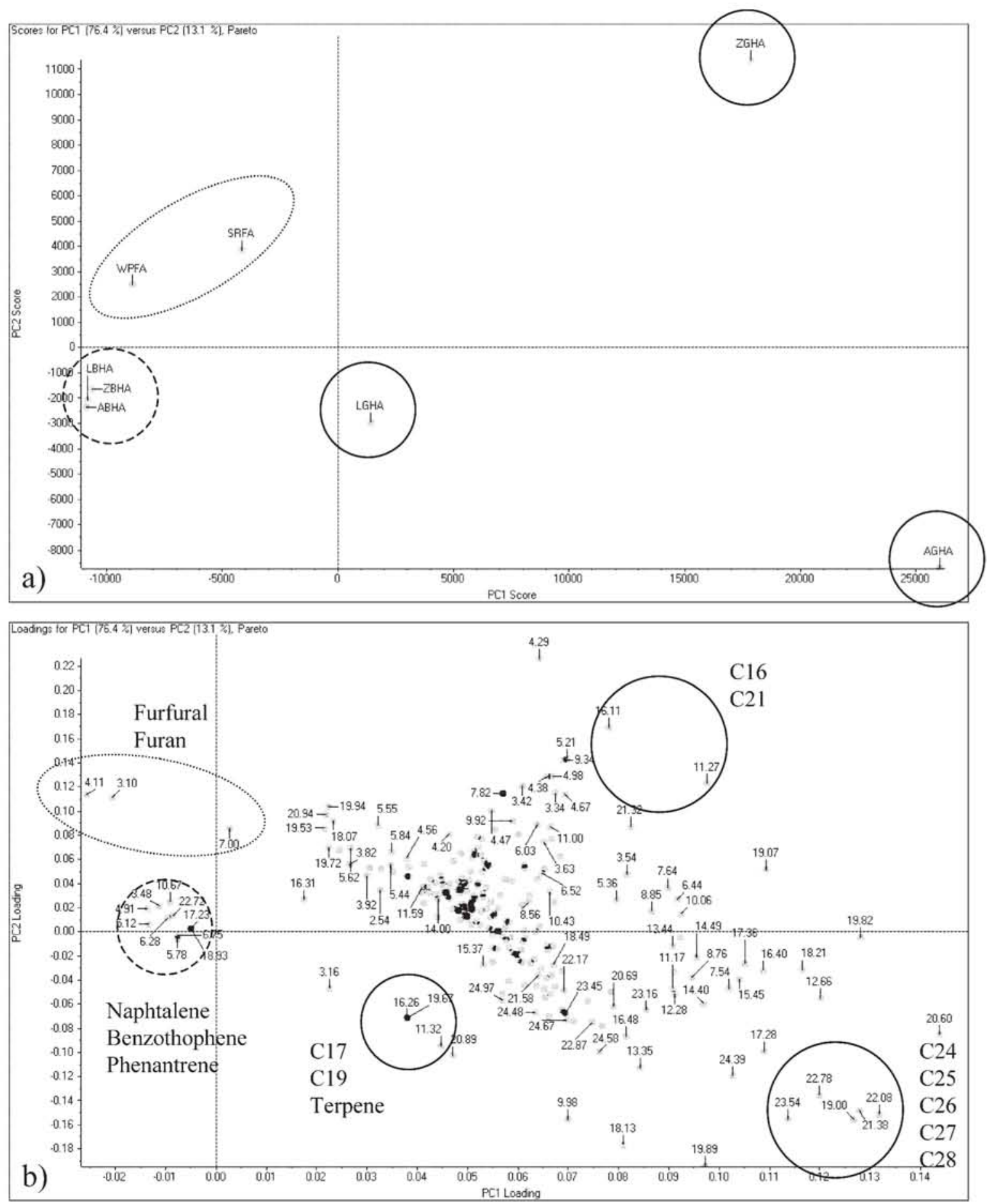

Fig. 4. MarkerView 1.1 principal component (PC) analysis graphics for pyrolysis gas chromatography-mass spectrometry: (a) sample grouping in PC scores, and (b) structural association sample signal in PC loadings (ABHA, Aldrich brown humic acid; AGHA, Aldrich gray humic acid; LBHA, leonardite standard brown humic acid; LGHA, leonardite standard gray humic acid; SRFA, Suwannee River reference fulvic acid; WPFA, Waskish peat reference fulvic acid; ZBHA, Czech brown humic acid; ZGHA, Czech gray humic acid). 
In relation to UV-Vis, in Fig. 5a we observe that the GHA fraction samples are grouped around 400 to $480 \mathrm{~nm}$, related to absorption of $n-\pi^{*}$ systems of polyenes and cyanines
(Prestch et al., 1991). The BHA samples are more grouped and associated with the 250- to 290-nm range, corresponding to transitions of $\pi-\pi^{*}$ aromatic systems (Prestch et al., 1991).
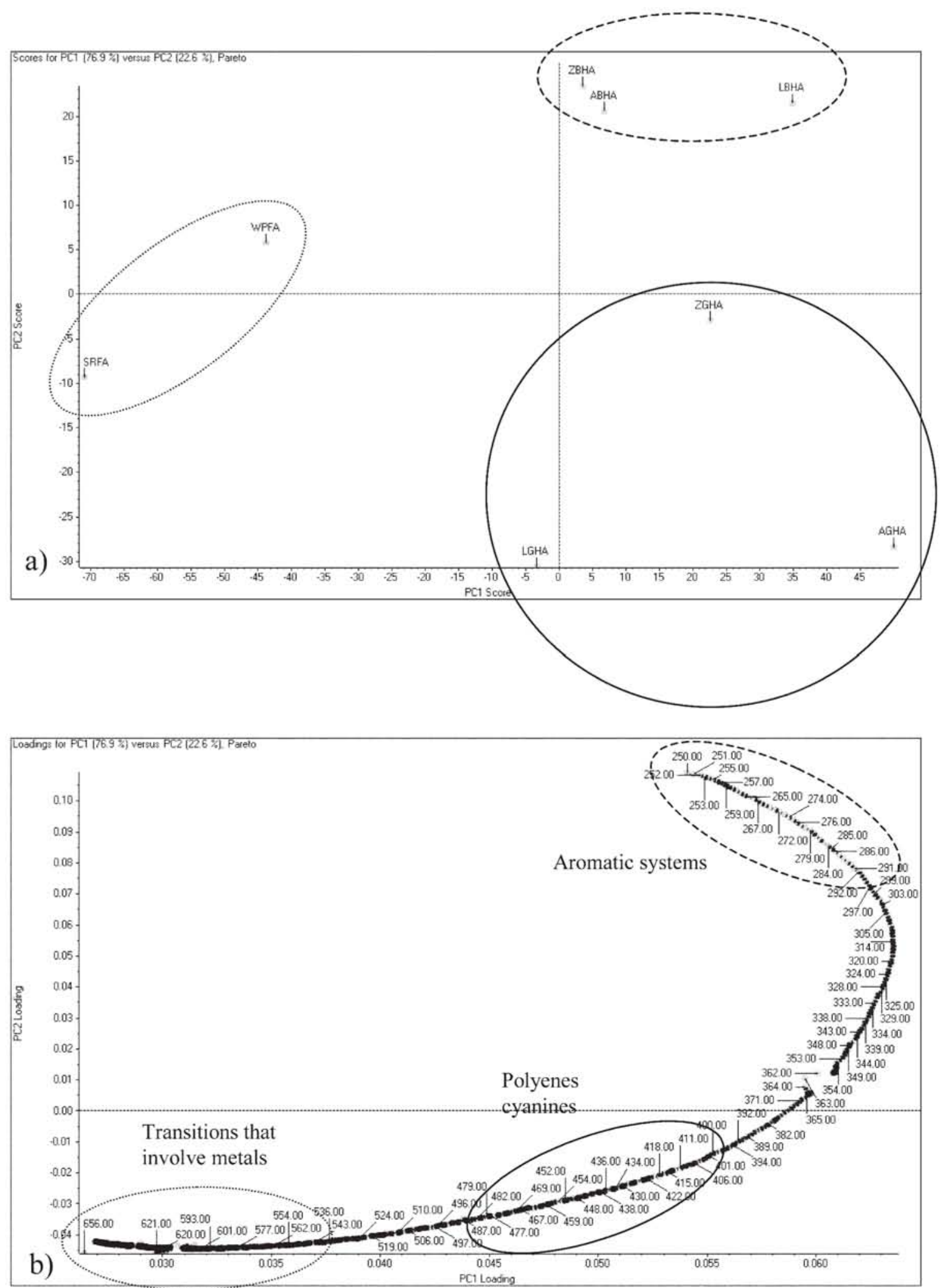

Fig. 5. MarkerView 1.1 principal component (PC) analysis graphics for ultraviolet-visible light spectroscopy: (a) sample grouping in PC scores, and (b) structural association sample signal in PC loadings (ABHA, Aldrich brown humic acid; AGHA, Aldrich gray humic acid; LBHA, leonardite standard brown humic acid; LGHA, leonardite standard gray humic acid; SRFA, Suwannee River reference fulvic acid; WPFA, Waskish peat reference fulvic acid; ZBHA, Czech brown humic acid; ZGHA, Czech gray humic acid). 
Table 1. Different fractions in humic substances and their characteristic structural groups by ${ }^{13} \mathrm{C}$ nuclear magnetic resonance spectrometry (NMR), synchronous fluorescence spectroscopy (SFS), Fourier-transform infrared spectroscopy (FTIR), pyrolysis gas chromatography-mass spectrometry (GC-MS), and ultraviolet-visible light spectroscopy (UV-Vis).

\begin{tabular}{|c|c|c|c|c|c|}
\hline Humic substance & ${ }^{13} \mathrm{C}-\mathrm{NMR}$ & SFS & FTIR & Pyrolysis GC-MS & UV-Vis \\
\hline Gray humic acid & $\begin{array}{l}\text { methyl } \\
\text { methylene }\end{array}$ & $\begin{array}{c}\text { naphthalene and } \\
\text { derivates }\end{array}$ & aliphatic $\mathrm{C}-\mathrm{H}$ & $\begin{array}{l}\text { alkanes and alkenes (C16-C28) } \\
\text { terpenes }\end{array}$ & $\begin{array}{l}\text { polyenes } \\
\text { cyanines }\end{array}$ \\
\hline Brown humic acid & aromatic & $\begin{array}{l}7 \text { benzene units } \\
\text { fused }\end{array}$ & aromatic $\mathrm{C}-\mathrm{H}$ & $\begin{array}{c}\text { anthracenes } \\
\text { benzotiophenes } \\
\text { phenantrenes }\end{array}$ & aromatic systems \\
\hline Fulvic acid & $\begin{array}{c}\text { saccharides } \\
\text { alcohols } \\
\text { ethers } \\
\text { carboxylic groups }\end{array}$ & $\begin{array}{c}\text { amino acids } \\
\text { simple benzenes } \\
5 \text { benzene units } \\
\text { fused }\end{array}$ & Carboxylic groups & $\begin{array}{l}\text { furfurals } \\
\text { furanes }\end{array}$ & $\begin{array}{l}\text { conjugated systems that } \\
\text { involve transition metals }\end{array}$ \\
\hline
\end{tabular}

Finally, the FA fraction appears more disperse and related to the 550- to 680-nm range, which is associated with transitions of $\pi-\pi^{*}$ conjugated systems and transitions that may involve metals (Prestch et al., 1991).

The results obtained clearly show that ${ }^{13} \mathrm{C}-\mathrm{NMR}$ is the best technique to group the different HS samples in their corresponding humic acid class (GHA, BHA, and FA) using Pareto analysis (Fig. 1a). Likewise, these results also show that BHA is the easiest fraction to be characterized because it appears grouped on the Pareto analysis for all analytical techniques used (Fig. 1a, 2a, 3a, $4 a$ and 5a), whereas FA is the most disperse fraction. Regarding GHA, the results were coherent but slightly different depending on the sample. Thus, in some cases ZGHA is located outside of the GHA group and close to BHA. These results indicate that BHA is the most homogeneous fraction and FA the most heterogeneous one. Likewise, they also indicate that BHA and GHA might be genetically associated with each other, since when the ZGHA sample appears out of GHA group, it always appears near the BHA group.

On the other hand, it is also noteworthy the very useful structural information that can be obtained from the application of Pareto analysis to the data derived from each analytical technique (Table 1). Thus, the GHA fraction is characterized by an important degree of aliphaticity $\left({ }^{13} \mathrm{C}-\mathrm{NMR}\right.$ and FTIR), a certain aromaticity but simpler (SFS: polycyclic aromatics consisting of about two fused benzene rings) than in BHA, and some conjugation in polyens and cianines (UV-Vis). The BHA fraction presents a greater and more complex aromatic character than GHA or FA $\left({ }^{13} \mathrm{C}-\mathrm{NMR}, \mathrm{FTIR}\right.$, and UV-Vis), involving polycyclic aromatics consisting of about seven fused benzene rings (SFS) and heterocycles such as benzotiophenes (SFS and pyrolysis GC-MS). Finally, the FA fraction is the most heterogeneous one. It contains simpler and less degraded and more functionalized organic molecules, such us polysaccharides, alcohols, and ethers ( $\left.{ }^{13} \mathrm{C}-\mathrm{NMR}\right)$; aromatic amino acids and some aromatic groups (SFS); carboxylic groups (FTIR); furfurals and furans (pyrolysis GC-MS); and finally, conjugated systems that may involve complexed metals (UV-Vis) as previously hypothesized (Simpson et al., 2002).

\section{Discriminant Analysis}

The application of discriminant analysis to Pareto data confirmed the above-mentioned results (Table 2). In Fig. 5, we present the different groups and the centroid corresponding to the different HS fractions (GHA, BHA, and FA) for each analytical technique.

In ${ }^{13} \mathrm{C}-\mathrm{NMR}, \mathrm{SFS}$, and pyrolysis GC-MS, the first function explains $>95 \%$ of the variance, showing a high eigenvalue. In the case of FTIR, the first function explains $75 \%$ of the variance but the corresponding eigenvalue is higher than the second-function eigenvalue. From UV-Vis, the first function explains $63.4 \%$ of

Table 2. Canonical discriminant analysis eigenvalues and Wilks' lambda significance from ${ }^{13} \mathrm{C}$ nuclear magnetic resonance spectrometry (NMR), synchronous fluorescence spectroscopy (SFS), Fourier-transform infrared spectroscopy (FTIR), pyrolysis gas chromatography-mass spectrometry (GC-MS), and ultraviolet-visible light spectroscopy (UV-Vis).

\begin{tabular}{|c|c|c|c|c|c|c|}
\hline \multirow{2}{*}{ Technique } & \multirow{2}{*}{ Function } & \multicolumn{4}{|c|}{ Eigenvalue } & \multirow{2}{*}{$\begin{array}{l}\text { Wilks' lambda } \\
\text { significance }\end{array}$} \\
\hline & & Value & Variance & Cumulative & Canonical correlation & \\
\hline & & & & & & \\
\hline \multirow[t]{2}{*}{${ }^{13} \mathrm{C}-\mathrm{NMR}$} & 1 & 881.5 & 96.5 & 96.5 & 0.999 & 0.001 \\
\hline & 2 & 32.26 & 3.5 & 100 & 0.985 & 0.033 \\
\hline \multirow[t]{2}{*}{ SFS } & 1 & 1333 & 99.7 & 99.7 & 1.000 & 0.003 \\
\hline & 2 & 4.422 & 0.3 & 100 & 0.903 & 0.280 \\
\hline \multirow[t]{2}{*}{ FTIR } & 1 & 106.6 & 74.8 & 74.8 & 0.995 & 0.006 \\
\hline & 2 & 35.99 & 25.2 & 100 & 0.986 & 0.029 \\
\hline \multirow{2}{*}{$\begin{array}{l}\text { Pyrolysis } \\
\text { GC-MS }\end{array}$} & 1 & 8.801 & 95.6 & 95.6 & 0.948 & 0.106 \\
\hline & 2 & 0.403 & 4.4 & 100 & 0.536 & 0.508 \\
\hline \multirow[t]{2}{*}{ UV-Vis } & 1 & 5.537 & 63.4 & 63.4 & 0.920 & 0.005 \\
\hline & 2 & 3.197 & 36.6 & 100 & 0.873 & 0.011 \\
\hline
\end{tabular}


a)

AGHA

LGHA
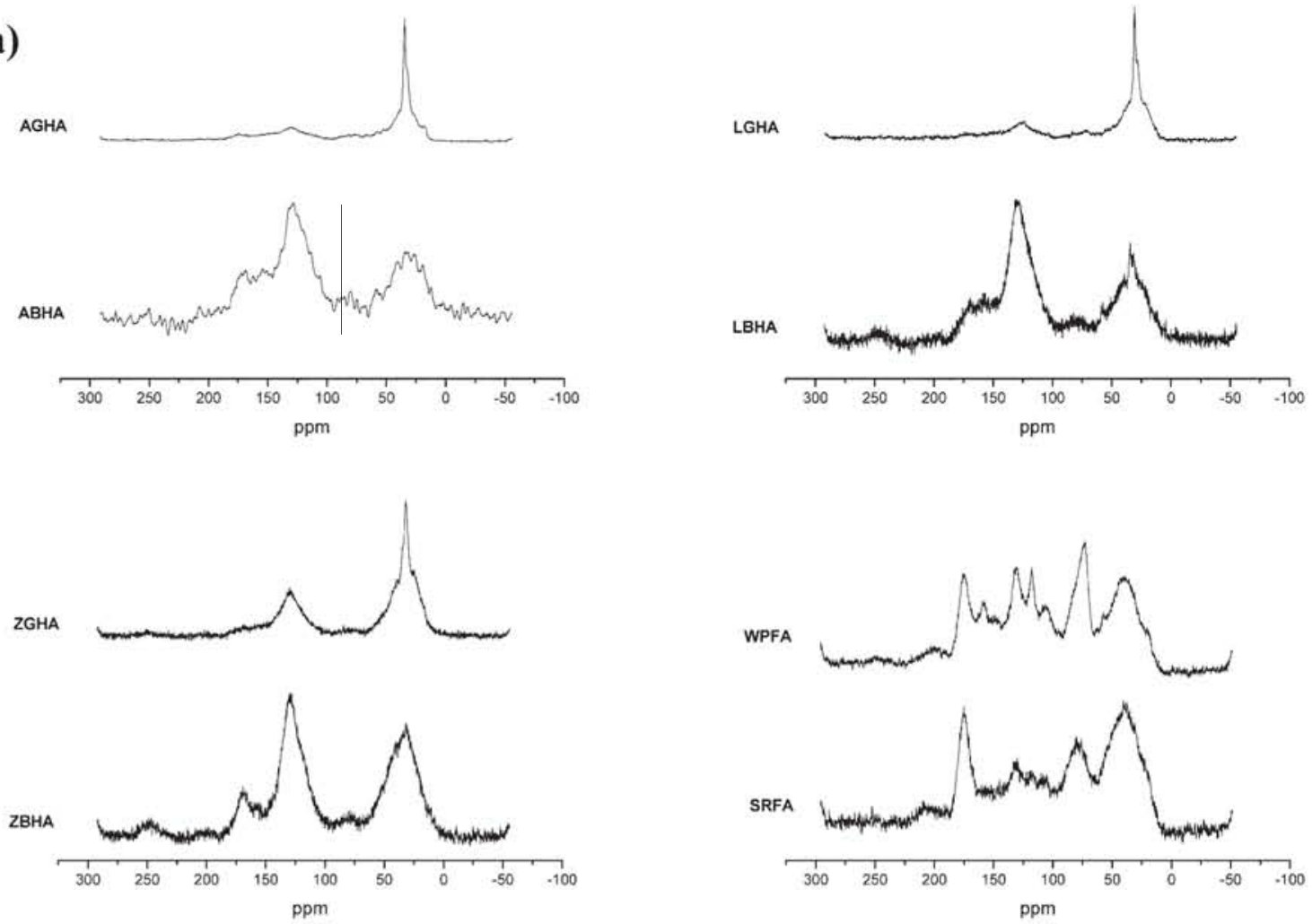

b)
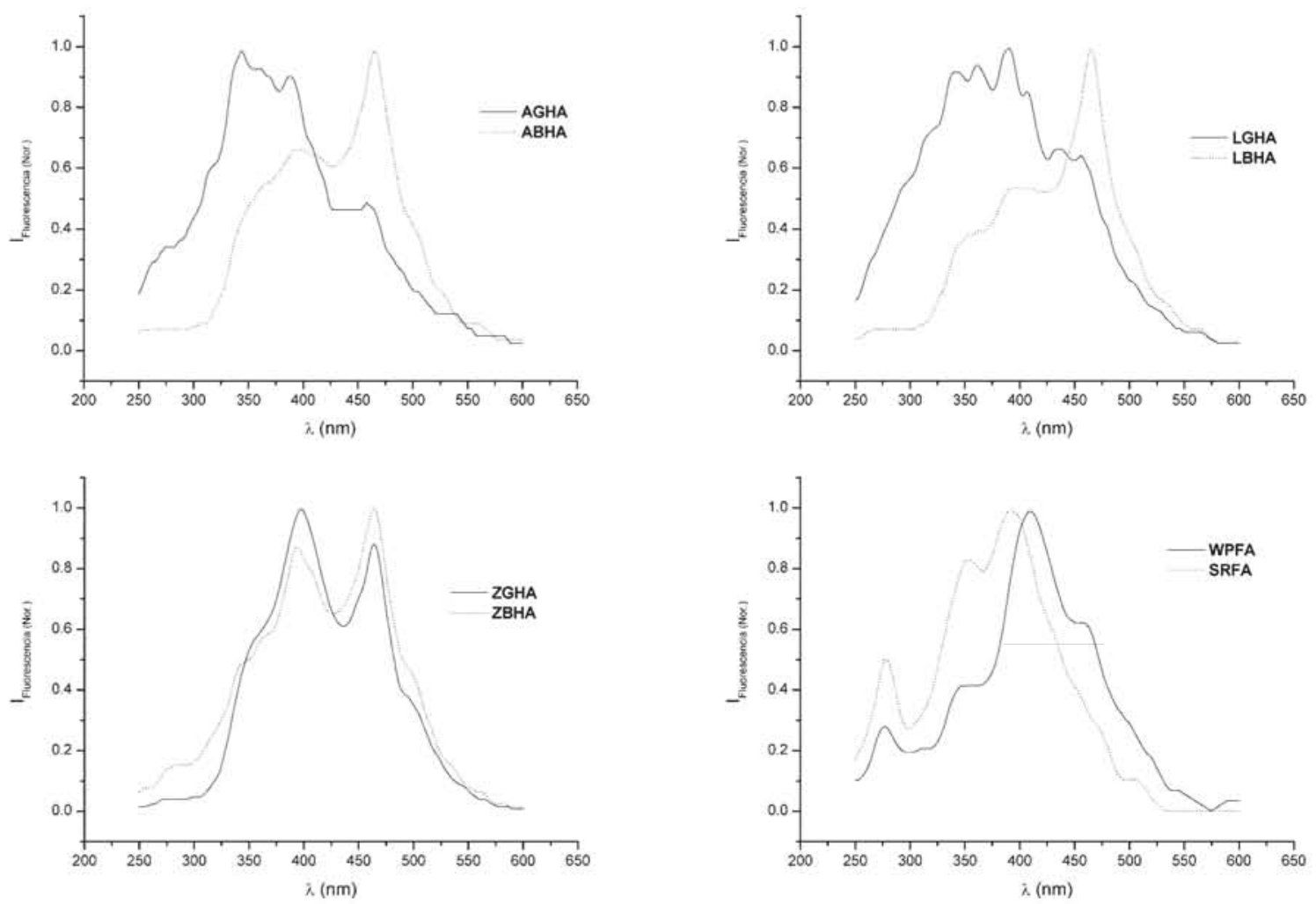

Fig. 7. Sample spectra for (a) ${ }^{13} \mathrm{C}$ nuclear magnetic resonance spectrometry, and (b) synchronous fluorescence spectroscopy (ABHA, Aldrich brown humic acid; AGHA, Aldrich gray humic acid; LBHA, leonardite standard brown humic acid; LGHA, leonardite standard gray humic acid; SRFA, Suwannee River reference fulvic acid; WPFA, Waskish peat reference fulvic acid; ZBHA, Czech brown humic acid; ZGHA, Czech gray humic acid). 



b)
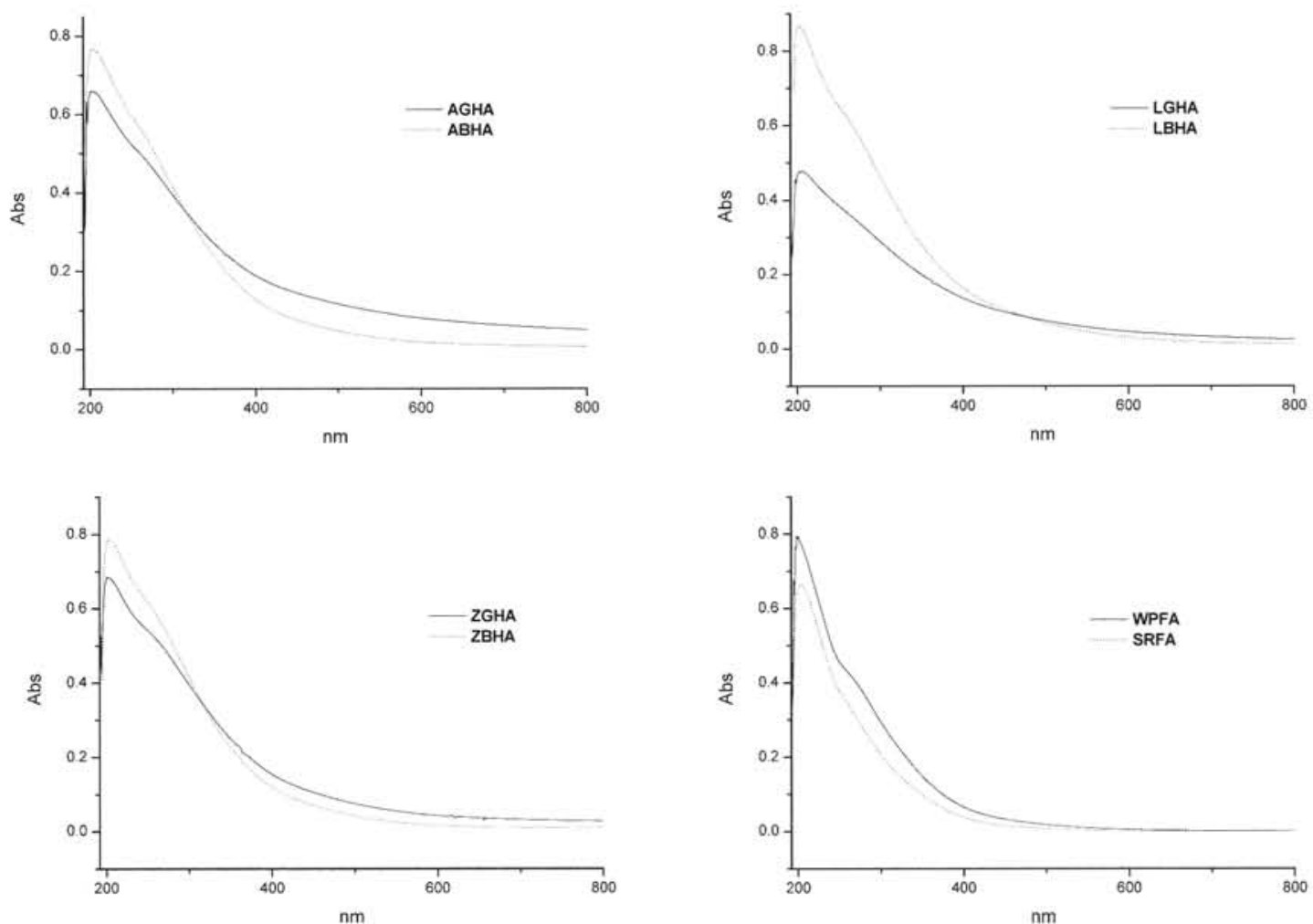

Fig. 8. Sample spectra for (a) Fourier-transform infrared spectroscopy, and (b) ultraviolet-visible light spectroscopy (ABHA, Aldrich brown humic acid; AGHA, Aldrich gray humic acid; LBHA, leonardite standard brown humic acid; LGHA, leonardite standard gray humic acid; SRFA, Suwannee River reference fulvic acid; WPFA, Waskish peat reference fulvic acid; ZBHA, Czech brown humic acid; ZGHA, Czech gray humic acid). 

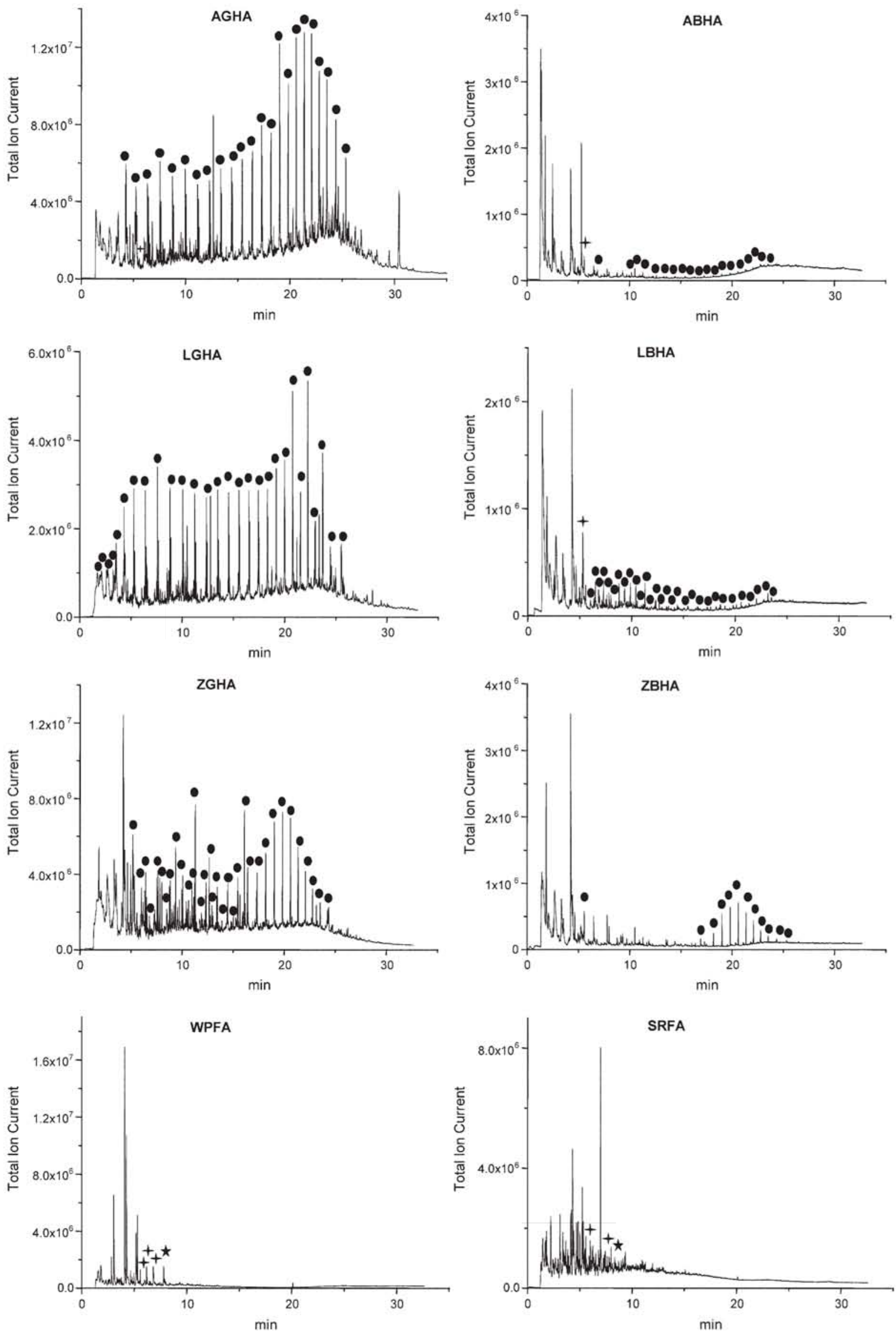

Fig. 9. Sample spectra for pyrolysis gas chromatography-mass spectrometry (ABHA, Aldrich brown humic acid; AGHA, Aldrich gray humic acid; LBHA, leonardite standard brown humic acid; LGHA, leonardite standard gray humic acid; SRFA, Suwannee River reference fulvic acid; WPFA, Waskish peat reference fulvic acid; ZBHA, Czech brown humic acid; ZGHA, Czech gray humic acid). (•Alkanes and alkenes; † guaiacols; $\star$ syringols). 


\section{ACKNOWLEDGMENTS}

We would like to thank David Rhymes and María Garnica for kindly improving the English of the manuscript.

\section{REFERENCES}

Baigorri, R., M. Fuentes, G. González-Gaitano, and J.M. García-Mina. 2007. Simultaneous presence of diverse molecular patterns in humic substances in solution. J. Phys. Chem. B 111:10577-10582.

Baigorri, R., A.M. Zamarreño, M. Fuentes, G. González-Gaitano, J.M. García-Mina, G. Almendros, and F.J. González-Vila. 2008. Multivariate statistical analysis of mass spectra as a tool for the classification of humic substances according to their structural and conformational features. J. Agric. Food Chem. 56:5480-5487.

Beauchemin, S., D. Hesterberg, and M. Beauchemin. 2002. Principal component analysis approach for modeling sulfur K-XANES spectra of humic acids. Soil Sci. Soc. Am. J. 66:83-91.

Boehme, J., P. Coble, R. Conmy, and A. Stovall-Leonard. 2004. Examining CDOM fluorescence variability using principal component analysis: Seasonal and regional modeling of three-dimensional fluorescence in the Gulf of Mexico. Mar. Chem. 89:3-14.

Celano, G., D. Šmejkalová, R. Spaccini, and A. Piccolo. 2008. Interactions of three $s$-triazines with humic acids of different structure. J. Agric. Food Chem. 56:7360-7366.

Karuppusami, G., and R. Gandhinathan. 2006. Pareto analysis of critical success factors of total quality management. TQM Mag. 18:372-385.

Lovley, D.R., J.D. Coates, E.L. Blunt-Harris, E.J.P. Phillips, and J.C. Woodward. 1996. Humic substances as electron acceptors for microbial respiration. Nature 382:445-448.

Lucio, M., and P. Schmitt-Kopplin. 2006. Modeling the binding of triazine herbicides to humic substances using capillary electrophoresis. Environ. Chem. Lett. 4:15-21.

Mahieu, N., D.C. Olk, and E.W. Randall. 2002. Multinuclear magnetic resonance analysis of two humic acid fractions from lowland rice soils. J. Environ. Qual. 31:421-430.

Mao, J.-D., W.-G. Hu, K. Schmidt-Rohr, G. Davies, E.A. Ghabbour, and B. Xing. 2000. Quantitative characterization of humic substances by solid-state carbon-13 nuclear magnetic resonance. Soil Sci. Soc. Am. J. 64:873-884.

Moreda-Piñeiro, A., E.M. Seco-Gesto, A. Bermejo-Barrera, and P. Bermejo-
Barrera. 2006. Characterization of surface marine sediments from Ría de Arousa estuary according to extractable humic matter content. Chemosphere 64:866-873.

Novák, J., J. Kozler, P. Janoš, J. Čežiková, V. Tokarová, and L. Mandronová. 2001. Humic acids from coals of the North-Bohemian coal field: I. Preparation and characterization. React. Funct. Polym. 47:101-109.

Peña-Méndez, E.M., D. Gajdošová, K. Novotná, P. Prošek, and J. Havel. 2005. Mass spectrometry of humic substances of different origin including those from Antarctica: A comparative study. Talanta 67:880-890.

Peuravuori, J.R.K., R. Koivikko, and K. Pihlaja. 2002. Characterization, differentiation and classification of aquatic humic matter separated with different sorbents: Synchronous scanning fluorescence spectroscopy. Water Res. 36:4552-4562.

Prestch,E., T. Clerc, J. Seibl, and W.Simon. 1991. Tabellen zur Strukturaufklărung organischer Verbindungen mit spektroskopische Methoden. SpringerVerlag, Berlin.

Schnitzer, M. 1991. Soil organic matter: The next 75 years. Soil Sci. 151:41-58.

Simpson, A.J., W.L. Kingery, M.H.B. Hayes, M. Spraul, E. Humpfer, P. Dvortsak, R. Kerssebaum, M. Godejohann, and M. Hofmann. 2002. Molecular structures and associations of humic substances in the terrestrial environment. Naturwissenschaften 89:84-88.

Šmejkalová, D., and A. Piccolo. 2008. Aggregation and disaggregation of humic supramolecular assemblies by NMR diffusion ordered spectroscopy (DOSY-NMR). Environ. Sci. Technol. 42:699-706.

Sparks, D.L. 1995. Environmental soil chemistry. Academic Press, San Diego.

Stevenson, F.J. 1994. Humus chemistry: Genesis, composition, reactions. John Wiley \& Sons, New York.

Swift, R.S. 1985. Fractionation of soil humic substances. p. 387-408. In G.R. Aiken et al. (ed.) Humic substances in soil, sediment and water: Geochemistry, isolation, and characterization. Wiley-Interscience, New York.

Swift, R.S. 1996. Organic matter characterization. p. 1011-1069. In D.L. Sparks (ed.) Methods of soil analysis. Part 3. Chemical methods. SSSA Book Ser. 5. SSSA, Madison, WI.

Wang, K., and B. Xing. 2005. Structural and sorption characteristics of adsorbed humic acid on clay minerals. J. Environ. Qual. 34:342-349.

White, D.M., I.D. Hodkinson, S.J. Seelen, and S.J. Coulson. 2007. Characterization of soil carbon from a Svalbard glacier-retreat chronosequence using pyrolysis-GC/MS analysis. J. Anal. Appl. Pyrolysis 78:70-75. 